\title{
$C_{0} \mathbf{I} \cdot \mathbf{R}^{\circ} \mathbf{P} \cdot \mathrm{E}^{\prime} \cdot \mathrm{E}$
}

Centre Interuniversitaire sur le Risque, les Politiques Économiques et l'Emploi

Cahier de recherche/Working Paper 10-08

\section{Corporate Risk Management and Dividend Signaling Theory}

Georges Dionne

Karima Ouederni

Février/February 2010

Dionne: HEC Montréal and CIRPÉE

georges.dionne@hec.ca

Ouederni: HEC Montréal 
Abstract: This paper investigates the effect of corporate risk management on dividend policy. We extend the signaling framework of Bhattacharya (1979) by including the possibility of hedging the future cash flow. We find that the higher the hedging level, the lower the incremental dividend. This result is in line with the purpoted positive relation between information asymmetry and dividend policy (e.g., Miller and Rock, 1985) and the assertion that risk management alleviates the information asymmetry problem (e.g., DaDalt et al., 2002). Our theoretical model has testable implications.

Keywords: Signaling theory, Dividend policy, Risk management policy, Corporate hedging, Information asymmetry

JEL Classification: G35, G32, D82

Résumé: Cet article étudie l'effet de la gestion des risques sur la politique du dividende de l'entreprise. Pour ce faire nous avons procédé à l'extension du modèle de signalisation de Bhattacharya (1979) en introduisant la possibilité de couverture du cash flow futur. Nous montrons que le niveau de couverture affecte négativement le taux de distribution du dividende. Ce résultat corrobore les études stipulant l'existence d'une relation positive entre le niveau d'asymétrie d'information et la politique du dividende (e.g., Miller et Rock, 1985) et celles confirmant que la gestion des risques allège le problème d'asymétrie d'information (e.g., DaDalt et al., 2002). Notre modèle théorique a des implications empiriques testables.

Mots clés: Théorie des signaux, Politique du dividende, Politique de gestion des risques, Couverture, Asymétrie d'information 


\section{Introduction}

Signaling theory states that changes in dividend policy convey information about changes in future cash flows (e.g., Bhattacharya, 1979, Miller and Rock, 1985). Dividend signaling suggests a positive relation between information asymmetry and dividend policy. ${ }^{1}$ In other words, the higher the asymmetric information level, the higher is the sensitivity of the dividend to future prospects of the firm. Several empirical studies attempt to test the informational content of dividend changes, yet they disagree about the sign and the significance of the effect of information asymmetry on dividend policy (see Allen and Michaely, 2003, for a survey).

Another strand of literature suggests that corporate risk management alleviates information asymmetry problems and hence positively affects the firm value. Information asymmetry between managers and outside investors is one of the key market imperfection that makes hedging potentially beneficial. DeMarzo and Duffie (1995) and Breeden and Viswanathan (1989) argue that hedging reduces noise around earnings streams and thus decreases the level of asymmetric information regarding the firm value. DaDalt et al. (2002) provide empirical evidence supporting these theoretical studies.

In this paper we exploit the documented interaction between the level of information asymmetry and the dividend policy, along with its interaction with corporate risk management. We argue that risk management alleviates the asymmetric information problem, which is a main determinant of dividend policy. Though many studies that examine dividend policy determinants include several measures of information asymmetry, none, to our knowledge, consider hedging among these measures. Extending the signaling framework of Bhattacharya (1979), we provide theoretical support for the effect of corporate risk management on dividend payout policy. We find a negative relation between the hedge ratio and the incremental dividend payout.

The remainder of the article is organized as follows. In the next section we present the theoretical model and its implications. The third section concludes.

\section{The model}

We assume that the firm operates in a dividend signaling world as modeled in Bhattacharya (1979). We assume that shareholders have a single-period planning horizon and the manager

${ }^{1}$ Evidence that information asymmetry positively affects dividend policy has also been documented by the free cash flow theory (e.g., Lang and Litzenberger, 1989). 
operates in the best interest of current shareholders. The model is developed in terms of marginal analysis for a new project taken on by the firm. We assume that the manager is better informed than outside investors about the firm's future prospects. Thus the manager is the only agent informed about the distribution of the new project future cash flow $(x)$. He attempts to signal his private information via the commitment of an incremental dividend $(D)$. Dividends are taxed at the rate $\tau$ while capital gains are not taxed. There is a penalty $(\beta)$ incurred by shareholders in case of cash flow shortfall to cover the committed dividend. $\beta$ could be considered as the cost of external financing. When the cash flow $(x)$ exceeds the committed dividend, the amount of future external financing is reduced by $(x-D)$ and vice versa.

We extend the model by assuming that it is possible for the manager to hedge a fraction $(h)$ of the future cash flow using a linear strategy. The reasoning behind this extension is simple. Outside investors often use estimates of earnings and cash flows as measures of firm value. Hedging reduces the noise around earnings and future cash flows by reducing the exposure of the firm to factors beyond the manager's control. Consequently, hedging lessens the asymmetric information regarding firm value by reducing the noise in evaluation measures. We expect that the more willing the firm is to hedge its future cash flow, the less informative the dividend changes and the lower the manager's incentives for costly signaling through dividends. We make the implicit assumption that corporate hedging activity is observable by outside investors. This assumption is realistic given the implementation of many disclosure requirement regulations by the Financial Accounting Standards Board (FASB) since the beginning of the '90s (e.g., FAS105, FAS107, FAS119, FAS133, FAS138 and FAS161).

Equation (1) illustrates the new uncertain cash flow resulting from the linear hedging strategy:

$$
\tilde{x}_{1}=h x_{0}+(1-h) \tilde{x}
$$

where $0 \leq h \leq 1$ is the hedge ratio and $x_{0}$ the expected cash flow.

The incremental part of the objective function of current shareholders is given by equation (2). The four terms in the equation are respectively: (i) the rise in the firm's liquidation value $V(D)$; (ii) the after-tax promised dividend; (iii) the expected gain when the hedged cash flow is greater than the committed dividend; and (iv) the expected loss when the hedged cash flow is lower than the committed dividend: 


$$
W(D, h)=\frac{1}{1+r}\left[\begin{array}{l}
V(D)+(1-\tau) D+\int_{x_{D}}^{\bar{x}}\left(x_{0} h+(1-h) x-D\right) f(x) d x \\
+(1+\beta) \int_{\underline{x}}^{x_{D}}\left(x_{0} h+(1-h) x-D\right) f(x) d x
\end{array}\right]
$$

where $r$ is the after-tax interest rate; $V(D)$ the response liquidation value of the firm resulting from the commitment and the payment of $D$, and $x_{D}$ the minimum cash flow needed to pay the promised dividend without penalty. Its value is given by equation (3):

$$
x_{D}=\frac{D-h x_{0}}{(1-h)}
$$

\subsection{Optimal dividend for a given hedge ratio}

Following Bhattacharya (1979) we assume that the future cash flow is uniformly distributed over $[0, \mathrm{t}]$. Thus the maximization problem is reduced to:

$$
\max _{D} W(D, h)=\frac{1}{1+r}\left[V(D)-\tau D+\frac{t}{2}-\frac{1}{8} \beta \frac{(2 D-t h)^{2}}{(1-h) t}\right]
$$

The first order condition solves:

$$
V^{\prime}\left(D^{*}\right)=\tau+\beta \frac{\left(2 D^{*}-t h\right)}{2(1-h) t}
$$

At the optimum, the marginal profit from the dividend increase (the increase of the firm value) equals its marginal cost (taxes and expected cost of external financing).

The second order condition is given by equation (6):

$$
\frac{\partial^{2}}{\partial D^{2}} W(D, h)=\frac{1}{1+r}\left[V^{\prime \prime}(D)-\frac{\beta}{(1-h) t}\right]
$$

Since $V(D)$ is increasing and concave, $h$ lower than one is a sufficient condition for the second order condition to be satisfied. The hedge ratio $h$ lies between 0 and 1 given that speculation and over hedging are not considered in this model.

\subsection{Signaling equilibrium}

The signaling equilibrium demands that $V\left(D^{*}(t)\right)$ must be "equal to the true value of future cash flows for the project whose cash flows are signaled with dividend $D$ "( Bhattacharya (1979), p. 264). Under the assumption of a stationary dividend, the equilibrium function $V\left(D^{*}(t)\right)$ is given by equation (7): 


$$
V\left(D^{*}(t)\right)=K\left[\frac{t}{2}-\tau D^{*}(t)-\frac{1}{8} \beta \frac{\left(2 D^{*}(t)-t h\right)^{2}}{(1-h) t}\right]
$$

where $K=1 / r$.

Differentiating equation (7) with respect to $t$ and substituting for $V^{\prime}\left(D^{*}\right)$ from equation (5), we obtain:

$$
(K+1)\left[\tau+\frac{\beta D}{(1-h) t}-\frac{1}{2} \beta \frac{h}{(1-h)}\right] \frac{d D}{d t}=K\left[\frac{1}{2}-\frac{1}{8} \frac{\beta h^{2}}{(1-h)}+\frac{\beta D^{2}}{2(1-h) t^{2}}\right]
$$

Assuming a linear solution for the first order differential equation (8), $D(t)=A \times t$, we obtain the following quadratic equation:

$$
\frac{(K+2)}{(K+1)} A^{2}+\left(\frac{2 \tau}{\beta}(1-h)-h\right) A-\frac{K}{\beta(K+1)}(1-h)+\frac{1}{4} \frac{K}{(K+1)} h^{2}=0
$$

The positive root of the quadratic equation is equal to:

$$
\begin{aligned}
A= & -\frac{2 \tau(1-h)-\beta h}{\beta} \times \frac{(K+1)}{2(K+2)}+ \\
& \frac{(K+1)}{2(K+2)} \times \sqrt{\left(\frac{2 \tau(1-h)-\beta h}{\beta}\right)^{2}-\frac{K(K+2)}{\beta(K+1)^{2}}\left(\beta h^{2}-4(1-h)\right)}
\end{aligned}
$$

When $h=0$ we obtain the corresponding values for (9) and (10) in Bhattacharya (1979).

$A$ is the incremental dividend payout. It also illustrates the sensitivity of dividend increases to earnings prospects. For reasonable values of tax rate $(\tau \leq 40 \%)$ and external financing cost $(\beta \leq 20 \%), A$ is decreasing in the hedge ratio. In Figure 1, we show the function with some feasible parameters. We observe a negative effect of the hedge ratio on the incremental dividend payout. This result is intuitive. It is in line with studies suggesting that cash flows' predictability decreases the marginal gain from costly signaling through dividends (e.g., Chang et al. 2006) and the assertion that corporate hedging decreases cash flows volatility and thus increases their predictability. 


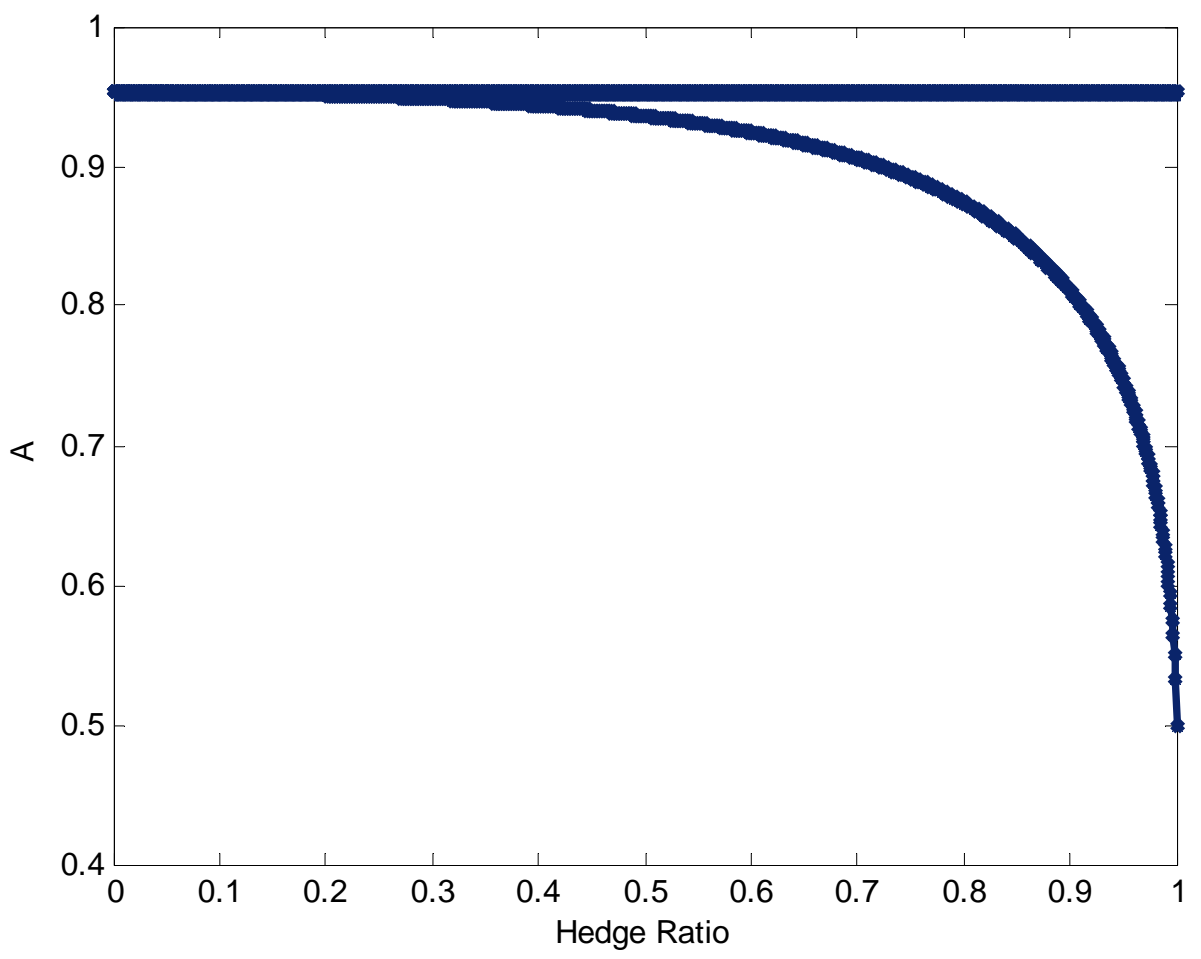

Figure 1

The curve illustrates $A$ for $0<h<1, \tau=40 \% ; \beta=20 \%$ and $r=5 \%$. The straight line illustrates $A$ for $h=0$ (Bhattacharya, 1979).

Notice that $A$ is not strictly decreasing in the hedging level for all values of tax rates and external financing costs. For high but less feasible values of $\tau>40 \%$ and $\beta>20 \%, A$ first increases and then decreases in $h$. For all values of the parameters, $A$ always converges to 0.5 when $h$ is near 1 .

\subsection{Optimal hedge ratio}

Another way to emphasize the interaction between the dividend policy and the corporate hedging policy is to maximize the incremental shareholders' wealth in (4) with respect to the hedge ratio. The first and second order conditions along with the signaling equilibrium condition provide the following optimal hedge ratio (See appendix for details):

$$
h^{*}=2\left(1-\frac{D}{t}\right)
$$

The optimal hedge ratio is decreasing in the dividend payout ratio. This result is in line with empirical studies suggesting a negative effect of the dividend policy on the hedge ratio (e.g., Dionne and Garand, 2003). It is also in line with dividend signaling theory intuition. It 
suggests that managers with higher expectations about future performance of the firm distribute higher dividends while reducing their hedge ratio. Thus, in a signaling world shareholders are better off when the firm deviates from the full hedging strategy. Finally, (11) indicates clearly that $D$ and $h$ are interdependent decision variables. In fact we can verify that $0<h^{*}<1$ as $1>\frac{D}{t}>\frac{1}{2}$.

\section{Conclusion}

The findings of this paper reconcile dividend signaling theory with risk management theory. We contribute to the dividend signaling literature by emphasizing the interaction between corporate risk management policy and dividend policy. The interaction between these two corporate policies has received less attention in the literature despite their common link to information asymmetry. Using an extension of Bhattacharya's signaling model, we find that the hedging of future cash flows reduces the sensitivity of dividends to future earnings. A straightforward implication of this result is that the informational content of dividend changes decreases with the hedge ratio. It leads to the empirical test of whether corporate risk management reduces the power of dividend changes to predict future changes in earnings. It thus represents a new test of the dividend signaling theory.

\section{References}

Allen, F., Michaely, R., 2003. Payout policy, in: G.M. Constantinides \& M. Harris \& R. M. Stulz, eds., Handbook of the Economics of Finance, Vol. 1, Chapter 7, 337-429.

Bhattacharya, S., 1979. Imperfect information, dividend policy and 'the bird in the hand' fallacy. Bell Journal of Economics 10, 259-70.

Breeden, D., Viswanathan, S., 1998. Why do firms hedge? An asymmetric information model. Working Paper, Fuqua School of Business, Duke University.

Chang, C., Kumar, P., Sivaramakrishnan, K., 2006. Dividend changes, cash flow predictability, and Signaling of Future Cash Flows. SSRN online library N ${ }^{0} 881511$.

DaDalt, P., Gay, G., Nam J., 2002. Asymmetric information and corporate use of derivatives. The Journal of Future Markets 22, 261-267.

DeMarzo, P., Duffie, D., 1995. Corporate incentives for hedging and hedge accounting. Review of Financial Studies, Fall, 743-771. 
Dionne, G., Garand, M., 2003. Risk management determinants affecting firms' values in the gold mining industry: new empirical evidence. Economics Letters 79: 43-52.

Lang, L., Litzenberger, R., 1989. Dividend announcements: cash flow signaling vs. free cash flow hypothesis? Journal of Financial Economics 24, 181-191.

Miller, M., Rock, K., 1985. Dividend policy under asymmetric information. The Journal of Finance 40, 1031-1051. 


\section{Appendix}

The first order condition of the maximization of (4) with respect to $h$ equals:

$$
\begin{aligned}
& \frac{\partial}{\partial h} W(D, h)=\frac{1}{1+r}\left[-\frac{1}{8} \beta \frac{-2 t(1-h)(2 D-t h)+(2 D-t h)^{2}}{(1-h)^{2} t}\right]=0 \\
& \Leftrightarrow(2 D-t h)(-2 t(1-h)+(2 D-t h))=0
\end{aligned}
$$

The second order condition with respect to $h$ is equal to:

$$
\frac{\partial^{2}}{\partial h^{2}} W(D, h)=-\frac{1}{8} \beta \frac{1}{1+r}\left(\frac{2 t^{2}(1-h)^{2}-8 D t+4 t^{2} h-2 t^{2} h^{2}+8 D^{2}}{(1-h)^{3} t}\right)
$$

The maximization problem has two complementary solutions:

$$
h^{*}=\left\{\begin{array}{l}
2 \frac{D}{t} \text { if } \frac{D}{t}<\frac{1}{2} \\
2\left(1-\frac{D}{t}\right) \text { if } \frac{D}{t}>\frac{1}{2}
\end{array}\right.
$$

When we substitute for $h=2 \mathrm{D} / \mathrm{t}$ in the equilibrium payout ratio (10) we get:

$$
A_{\mid h=2 \frac{D}{t}}=\frac{1}{2} \frac{K}{(K+1) \tau}
$$

It is straightforward to show that $A$ is bigger than 0,5 . Notice that $A=D^{*} / t$ and when it is bigger than $1 / 2$ the second order condition of the maximization of shareholders' wealth with respect to $h$ is not satisfied so we do not retain this potential solution.

When we substitute for $h=2(1-D / t)$ in the equilibrium payout ratio (10) we get:

$$
A_{h=2-2 \frac{D}{t}}=\frac{1}{2} \frac{K(1+\beta)}{(1+K)(\tau+\beta)}
$$

It is straightforward to show that for feasible values of $\beta$ and $\tau, A$ is bigger than 0,5 which satisfies the second order condition of the maximization of shareholders' wealth with respect to $h$. 